\title{
THE THIRTY-SIXTH SUMMER MEETING OF THE AMERICAN MATHEMATICAL SOCIETY
}

The thirty-sixth summer meeting and fourteenth colloquium of the Society were held at Brown University, Providence, Rhode Island, from Tuesday to Friday, September 9-12, 1930, preceded by the summer meeting of the Mathematical Association of America.

This was the second meeting of the Society held at Brown University, the first being in the summer of 1914 on the occasion of the celebration of the 150th anniversary of the founding of the institution. Of the fifty members in attendance at that meeting, nineteen were present this year. It is worthy of note that the number of members present sets a record nearly fifty percent higher than that of any previous summer meeting.

The colloquium lectures by Professor Solomon Lefschetz were delivered on Tuesday and Thursday afternoons and Wednesday and Friday mornings with one hundred fifty one members in attendance; these lectures will appear in book form within a few months. By invitation of the Committee on Program, Professors T. H. Hildebrandt and J. D. Tamarkin gave addresses entitled Linear transformations in general spaces, and Distribution of characteristic values of linear integral equations. Sectional sessions for Analysis were held on Tuesday afternoon and Thursday and Friday mornings; for Geometry, for Foundations, and Point Sets on Tuesday afternoon; for Algebra on Thursday morning; for Applied Mathematics on Friday morning.

During the latter part of Monday afternoon Mr. Norman Isham, Providence architect and a recognized authority on colonial architecture and furniture, led a group of visiting mathematicians and their friends on a walk through the old part of Providence to observe some of the more interesting examples of colonial architecture. On Monday evening President and Mrs. Barbour of Brown University tendered a reception to the guests in Alumnæ Hall. Wednesday afternoon was devoted to an excursion to Newport where the visitors availed themselves of the various opportunities for sight seeing and where a Rhode Island shore dinner was served. 
A picture was taken on the steps of Alumnæ Hall on Tuesday, a copy of which is to be inserted later in this Bulletin. In the late afternoon tea was served by the ladies of the Department of Mathematics of Brown University.

The Rhode Island School of Design admitted visiting mathematicians to its museum of art and colonial furniture without fee; and through the courtesy of the University and other local organizations golf and tennis were available to members without charge.

The fine collection in the mathematical department library was open to visitors, who were received by Professor R. C. Archibald.

The dormitories at Pembroke College were open for the visitors and meals were served in the cafeteria. Alumnæ Hall served as a delightful social center. The sessions were held in the Jesse Metcalf Chemical Laboratory and the Arnold Biological Laboratory on the main campus of the University.

The attendance included the following two hundred eighteen members of the Society:

C. R. Adams, R. B. Adams, P. L. Alger, E. L. Anderton, R. C. Archibald, C. L. Bacon, W. D. Baten, A. A. Bennett, Theodore Bennett, A. C. Berry, E. M. Berry, G. D. Birkhoff, H. F. Blichfeldt, G. A. Bliss, M. G. Boyce, Laura Brant, R. W. Brink, A. B. Brown, J. A. Bullard, L. H. Bunyan, W. H. Bussey, S.S. Cairns, W.D. Cairns, B.H. Camp, C.C. Camp, A. D. Campbell, G. A. Campbell, G. N. Carmichael, A. B. Chace, W. F. Cheney, L. P. Copeland, C. H.Currier, H. B. Curry, H. T. Davis, F.F. Decker, L.S. Dederick, Arnold Dresden, W. H. Durfee, L. A. Dye, Allegra Eckles, John Eiesland, H. T. Engstrom, H. P. Evans, D. A. Flanders, W. W. Flexner, A. L. Foster, Philip Franklin, Orrin Frink, T. C. Fry, C. A. Garabedian, H. A. Garabedian, H. M. Gehman, J. J. Gergen, B. P. Gill, D. C. Gillespie, R. E. Gilman, O. E. Glenn, J. W. Glover, M. C. Graustein, W. C. Graustein, B. F. Groat, H. A. Grout, E. S. Hammond, E. R. Hedrick, A. O. Hickson, T. H. Hildebrandt, Einar Hille, T. R. Hollcroft, C. T. Holmes, H. L. Holmes, Aline Huke, E. V. Huntington, H. B. Huntley, W. A. Hurwitz, J. I. Hutchinson, M. H. Ingraham, Dunham Jackson, R. L. Jeffery, R. A. Johnson, F. E. Johnston, F. C. Jonah, Herman Karnow, O. D. Kellogg, A. J. Kempner, Claribel Kendall, L. S. Kennison, M. V. Kenny, T. H. Kiang, B. F. Kimball, S. H. Kimball, F. W. Kokomoor, H. L. Krall, H. W. Kuhn, J. H. Kusner, W. D. Lambert, K. W. Lamson, A. W. Landers, R. E. Langer, Solomon Lefschetz, E. E. Libman, R. B. Lindsay, S. B. Littauer, M. I. Logsdon, C. I. Lubin, J. J. Luck, E. O. McCormick, John McDonnell, L. A. Mac Coll, C. C. MacDuffee, H. P. Manning, Morris Marden, E. N. Martin, A. E. Meder, H. A. Merrill, E. J. Miles, Norman Miller, E. B. Mode, E. C. Molina, C. L. E. Moore, C. N. Moore, L. T. Moore, R. K. Morley, Richard Morris, Marston Morse, David Moscovitz, A. F. 
Moursund, F. H. Murray, J. R. Musselman, J. H. Neelley, C. O. Oakley, P. S. Olmstead, H. L. Olson, F. W. Owens, H. B. Owens, F. W. Perkins, H. R. Phalen, James Pierpont, Hillel Poritsky, G. B. Price, S. M. Rambo, W. R. Ransom, Nicholas Rashevsky, S. E. Rasor, A. G. Rau, T. H. Rawles, C. J. Rees, M. S. Rees, C. N. Reynolds, Harris Rice, R. G. D. Richardson, D. E. Richmond, L. V. Robinson, Robin Robinson, C. F. Roos, George Rutledge, S. A. Schelkunoff, C. H. W. Sedgwick, C. E. Seely, Edward Sellers, I. M. Sheffer, W. A. Shewhart, W. G. Simon, L. G. Simons, T. M. Simpson, E. B. Skinner, H. E. Slaught, H. L. Slobin, M. M. Slotnick, C. H. Smiley, A. H. Smith, C. E. Smith, J. J. Smith, W. M. Smith, Virgil Snyder, I. S. Sokolnikoff, Joseph Spear, M. J. Sperry, C. C. Spooner, A. H. Sprague, E. T. Stafford, M. E. Stark, O. H. Stecker, M. E. Steinmetz, M. H. Stone, W. P. Suesman, M. C. Suffa, J. D. Tamarkin, H. B. Thiessen, T. Y. Thomas, M. M. Torrey, J. I. Tracey, W. J. Trjitzinsky, B. M. Turner, Oswald Veblen, C. H. Vehse, G. W. Walker, H. S. Wall, J. L. Walsh, A. C. Washburne, C. W. Watkeys, Warren Weaver, D. W. Weeks, V. H. Wells, R. A. Whelan, H. S. White, Hassler Whitney, Norbert Wiener, E. P. Wiggin, C. E. Wilder, R. L. Wilder, W. L. G. Williams, A. H. Wilson, E. W. Wilson, W. A. Wilson, R. G. Wood, F. S. Woods, F. M. Wright, J. W. Young.

The Secretary announced the election of the following fortyfour persons to membership in the Society:

Mr. Howard Holston Alden, Massilon, Ohio;

Professor Hugh R. Beveridge, Monmouth College;

Mr. Walter Edwin Bobertz, Westinghouse Electric Company, Wilkinsburg, Pennsylvania;

Professor Raymond Willis Boydston, Miami University;

Mr. Harry Edward Burton, U. S. Naval Observatory, Washington;

Miss Elizabeth Morgan Cooper, University of Illinois;

Dr. Max Coral, University of Chicago;

Professor Byron Cosby, State Teachers College, Kirksville, Missouri;

Mr. Bolivar Lang Falconer, Marlin, Texas;

Professor Ragnar A. K. Frisch, Yale University;

Professor George Haley, St. Ignatius University;

Mr. Lawrence DeLoss Hampton, Alabama Polytechnic Institute;

Miss Elizabeth Leigh Harris, Southwestern Bell Telephone Company, St. Louis;

Professor Akira Hirayama, Yamagata Women's Normal School;

Professor Warren Gengembre Hubert, College of the City of New York;

Professor James Alexander Hurry, Western State College, Colorado;

Mr. Horace A. Johnson, Los Angeles;

Mr. Maurice Keesing, New York City;

Miss Esther Ober McCormick, Barnard College;

Reverend Paul A. McNally, Georgetown College;

Mr. Edwin W. Miller, University of Michigan;

Mr. Edward Morris, Willits Water Company, Willits, California;

Professor Albert Henry Mowbray, University of California; 
Mr. Milton Clarke Nichols, Worcester Electric Light Company, Worcester, Massachusetts;

Professor H. Randolph Pyle, Penn College, Oskaloosa, Iowa;

Professor Calvin Gilbert Reen, Gettysburg College;

Professor Henry Schultz, University of Chicago;

Mr. Jesse W. Shuman, Minneapolis;

Professor Edmond Siroky, Washington University;

Professor Charles H. Smiley, Brown University;

Mr. Paul Szabo, Jr., New York City;

Mr. Henry Bertrand Thiessen, Brown University;

Professor Herbert Anderson Toops, Ohio State University;

Mr. Robert J. Walker, Mt. Lebanon, Pittsburg, Pa.;

Mr. Nicholas Weeks Wells, The Texas Company, Port Arthur, Texas;

Mr. Ronald F. Wick, Agricultural and Mechanical College of Texas;

Mr. Frank Leo Wilmer, Odebolt, Iowa;

Mr. Zarmair Zakarian, New York City;

Nominee of the Department of Mathematics, Brown University: $\mathrm{Mr}$. Harold F. S. Jonah;

Nominee of the Department of Mathematics, University of Wisconsin: Mr. Hugh Lonsdale Turrittin;

Nominees of the University of Michigan: Mr. Dawson Gerald Fulton, Mr. Emanuel Henry Hildebrandt, Mr. Charles Conroy Wagner and Mr. Ehrhardt H. Wagner.

The following members of the London Mathematical Society have accepted membership under the reciprocity agreement:

Professor K. Ananda-Rau, Presidency College, Madras, India;

Professor Edward Foyle Collingwood, Trinity College, Cambridge.

It was announced that Professor E. B. Wilson of the Graduate School of Medicine of Harvard University has accepted the invitation of the Society to give the eighth Josiah Willard Gibbs Lecture in connection with the annual meeting in Cleveland.

The following appointments were announced: to represent the Society at the dedication of the new campus at the University of Rochester, Professor Virgil Snyder; as Committee on Arrangements for the summer meeting of 1931, Professors R. W. Brink (chairman), H. H. Dalaker, M. H. Ingraham, H. L. Rietz and E. B. Stouffer.

Invitations for the summer meeting of 1932 were received from the University of California and from the University of California at Los Angeles. These invitations were accepted and a committee was appointed to work out the details of a 
meeting to include both institutions as well as excursions to other neighboring universities. This committee consists of Professors L. D. Ames, E. T. Bell, H. F. Blichfeldt, P. H. Dans and T. M. Putnam (chairman).

The prices of the Bulletin and Transactions beginning with 1931 were fixed at $\$ 9.00$.

It was announced that for 1930-31 the National Academy of Sciences had allotted to the Society from the funds donated by the General Education Board the sum of $\$ 4500$, to be distributed as follows: Bulletin, $\$ 500$; Transactions, $\$ 1500$; American Journal of Mathematics, $\$ 1500$; Colloquium Publications, $\$ 1000$.

The Society agreed to cooperate with the Society for the Promotion of Engineering Education which plans to hold a summer school of two weeks for the teachers of mathematics to engineering students, immediately preceding the summer meeting in Minneapolis, September 7-11, 1931. An advisory committee was appointed consisting of Professor W. D. Cairns, Dr. T. C. Fry, Professors E. R. Hedrick, E. V. Huntington, R. G. D. Richardson and J. W. Young.

A list of nominations for trustees, and officers and other members of the Council was adopted and ordered printed on the ballot.

The weather left nothing to be desired, and the local committee with Professor C. R. Adams as chairman had made careful plans for the arrangements for the meetings.

Resolutions were passed expressing appreciation of the cordial hospitality of the University and of the various other institutions which contributed to the success of the occasion.

The titles and cross references to abstracts of the papers read at the sessions follow below. The papers whose abstract numbers were followed by the letter $t$ were read by title; the papers numbered 1 to 6,22 to 45,59 to 63 , and 72 to 78 were read before the section for Analysis, President Hedrick and Professors Birkhoff, Bliss, and Kellogg presiding; those numbered 7 to 21 were read before the section for Geometry, Foundations, and Point Sets, Professor Graustein presiding; those numbered 46 to 58 before the section for Algebra, Professor Snyder presiding; those numbered 64 to 71 before the section for Applied Mathematics, Professor Weaver presiding; Professor Griffin's paper was read by Professor V. H. Wells. Mr. Cleve- 
land was introduced by Professor R. L. Moore, Dr. Féraud and Miss Wilder by Professor Jackson, Mr. Bisshopp by President Hedrick.

1. Note on the number of linearly independent Dirichlet series that satisfy certain functional equations, by Professor J. I Hutchinson. (Abstract No. 36-7-311.)

2. On certain equivalent methods of summation, by Professor C. N. Moore. (Abstract No. 36-9-317.)

3. On the summability of Fourier series. Third note, by Professors Einar Hille and J. D. Tamarkin. (Abstract No. 36-9318.)

4. Note on the convergence of a sequence of approximating polynomials, by Professor Dunham Jackson. (Abstract No. 369-319.)

5. An application and an extension of Pierpont's theory of integration, by Professor R. L. Jeffery. (Abstract No. 36-9-320.)

6. As to a "Goldschmidt solution" for a wire of minimum attraction, by Professor F. L. Griffin. (Abstract No. 36-9-321.)

7. Pencils of hypersurfaces, by Professor T. R. Hollcroft. (Abstract No. 36-9-322.)

8. Closed circuits upon polyhedra, by Professor C. N. Reynolds. (Abstract No. 36-7-316.)

9. On a certain class of ruled $V_{n-1}^{n-1}$ in $S_{n}$. Second paper, by Professor John Eiesland. (Abstract No. 36-7-309.)

10. An axiomatic basis for euclidean plane geometry, by Dr. S. S. Cairns. (Abstract No. 36-9-323.)

11. Functionality in combinatory logic, by Professor H. B. Curry. (Abstract No. 36-9-324-t.)

12. A converse of the theorem regarding the separation of $E_{3}$ by a closed two-dimensional manifold of genus $p$, by Professor R. L. Wilder. (Abstract No. 36-3-196.)

13. On the regular points of a continuum, by Professor W. L. Ayres. (Abstract No. 36-7-307-t.)

14. Element transformations and isogonal series, by Professor Edward Kasner. (Abstract No. 36-7-313-t.)

15. Concerning the possibility of a certain binary quartic being a line section of the plane quartic curve of genus zero, by Professor J. H. Neelley. (Abstract No. 36-9-325-t.)

16. A continuous development of mathematical logic in finite terms, by Mr. A. L. Foster. (Abstract No. 36-9-326-t.) 
17. A property of continua similar to local connectivity, by Professor W. A. Wilson. (Abstract No. 36-9-327-t.)

18. Semi-metric spaces, by Professor W. A. Wilson. (Abstract No. 36-9-328-t.)

19. Concerning continuous curves without local separating points, by Professor G. T. Whyburn. (Abstract No. 36-9329-t.)

20. Concerning the subsets of regular curves, by Professor G. T. Whyburn. (Abstract No. 36-9-330-t.)

21. On the existence of acyclic curves satisfying certain conditions with respect to a given coniinuous curve, by Mr. C. M. Cleveland. (Abstract No. 36-9-331-t.)

22. Concerning a certain integral equation, by Dr. L. H. Bunyan. (Abstract No. 36-9-332.)

23. On certain differential equations, by Dr. J. A. Shohat. (Abstract No. 36-9-333-t.)

24. The inversion of a differential operator of infinite order of Fuchsian type, by Professor H. T. Davis. (Abstract No. 369-334.)

25. The problems of Lagrange and Mayer under general end conditions, by Professor Marston Morse. (Abstract No. 36-9335.)

26. Prime number theory and Planck's law, by Professor Norbert Wiener. (Abstract No. 36-9-336.)

27. Preliminary report on a new method in the theory of central orbits, by Professor O. E. Glenn. (Abstract No. 36-7-310.)

28. A matrix theory of measurement, by Professor A. H. Copeland. (Abstract No. 36-9-337-t.)

29. Summation factors which are powers of a complex variable, by Professor W. H. Durfee. (Abstract No. 36-9-338.)

30. Some properties of the oscillation of harmonic functions, by Dr. F. W. Perkins. (Abstract No. 36-9-339.)

31. The generalized Euler differential equation of infinite order, by Professor H.T. Davis. (Abstract No.36-9-340-t.)

32. On Stieltjes' differential equation, by Dr. Morris Marden. (Abstract No. 36-9-341-t.)

33. Note on the methods of Sturm, by Professor C. O. Oakley. (Abstract No. 36-9-342-t.)

34. On interlinkings, by Professor G. Y. Rainich. (Abstract No. 36-7-315-t.) 
35. Note on the overconvergence of sequences of polynomials of best approximation, by Professor J. L. Walsh. (Abstract No. 36-9-343-t.)

36. The approximation of harmonic functions in three dimensions by harmonic polynomials, by Professor C. T. Holmes. (Abstract No. 36-9-344-t.)

37. Poincaré's rotation number and Morse's type number, by Dr. G. A. Hedlund. (Abstract No. 36-9-345-t).

38. Geodesics on a two-dimensional Riemannian manifold with periodic coefficients, by Dr. G. A. Hedlund. (Abstract No. 36-9-346-t.)

39. On Birkhoff's Pfaffian systems, by Dr. Lucien Féraud. (Abstract No. 36-9-347-t.)

40. On the symmetric form of the Fourier sine and cosine transforms, by Dr. S. B. Littauer (National Research Fellow). (Abstract No. 36-9-348-t.)

41. The effects of general regular transformations on oscillations of sequences of functions, by Dr. R. P. Agnew (National Research Fellow). (Abstract No. 36-9-349-t.)

42. Note on the existence of a positive function orthogonal to a given set of functions, by Dr. N. H. McCoy (National Research Fellow). (Abstract No. 36-9-350-t.)

43. Theorems concerning functional geodesic coordinates, by Professor A. D. Michal. (Abstract No. 36-7-303-t.)

44. Scalar functional invariants of a continuous one-parameter family of functional vectors, by Professor A. D. Michal. (Abstract No. 36-7-304-t.)

45. An introduction to differential geometries of composite spaces. Preliminary report, by Professor A. D. Michal. (Abstract No. 36-7-305-t.)

46. An elementary theorem on matrices, by Professor M. H. Ingraham. (Abstract No. 36-7-312.)

47. The construction of a headless and groupless triad system on 31 elements, by Professor H. S. White. (Abstract No. 369-351.)

48. Residue systems for a prime modulus, by Professor A. J. Kempner. (Abstract No. 36-9-352.)

49. On sequences defined by linear recurrence relations, by $\mathrm{Dr}$. H. T. Engstrom (National Research Fellow). (Abstract No. 36-9-353.) 
50. Algebraic Pfaffians, by Professors C. L. E. Moore and Philip Franklin. (Abstract No. 36-9-354.)

51. Expansions of arithmetical functions in infinite series, by Professor R. D. Carmichael. (Abstract No. 36-9-355-t.)

52. On the representation of integers as sums of an even number of squares or of triangular numbers, by Professor R. D. Carmichael. (Abstract No. 36-9-356-t.)

53. Concerning quasi-k-fold transitivity of permutation groups, by Professor R. D. Carmichael. (Abstract No. 36-9-357-t.)

54. On a question related to Waring's problem, by Professor R. D. Carmichael. (Abstract No. 36-9-358-t.)

55. Abstract defining relations for the simple group of order 5616, by Mr. K. E. Bisshopp. (Abstract No. 36-7-308-t.)

56. The characteristic roots of a matrix, by Professor E. T. Browne. (Abstract No. 36-9-359-t.)

57. On the separation property of the roots of the secular equation, by Professor E. T. Browne. (Abstract No. 36-9-360-t.)

58. On some general commutation formulas, by Dr. N. H. McCoy (National Research Fellow). (Abstract No. 36-7-314-t.)

59. Projective transformations in function space, by Dr. L. S. Kennison. (Abstract No. 36-7-306.)

60. Semi-linear integral equations, by Professor C. O. Oakle y. (Abstract No. 36-9-361.)

61. Convergence and summability criteria for Fourier series, by Dr. J. J. Gergen (National Research Fellow). (Abstract No. 36-9-362.)

62. A useful formula in the theory of finite differences, by Professor B. F. Kimball. (Abstract No. 36-9-363.)

63. A rule of signs involving cerlain orthogonal polynomials, by Dr. Morris Marden. (Abstract No. 36-9-364.)

64. A study of the interference of polarized light by the method of coherency matrices, by Dr. Dorothy W. Weeks. (Abstract No. 36-9-365.)

65. On the flow of heat for a solid in contact with a liquid, by Professor R. E. Langer. (Abstract No. 36-9-366.)

66. Some differential and algebraic consequences of the Einstein field equations, by Professor K. W. Lamson. (Abstract No. 36-9-367.)

67. Some new mathematical problems in biophysics, by $\mathrm{Mr}$. Nicholas Rashevsky. (Abstract No. 36-9-368.) 
68. Mean value of the ordinate of the locus of the rational integral algebraic function of degree $n$, expressed as a weighted mean of $n+1$ ordinates, and the resulting rules of quadrature, by $\mathrm{Mr}$. B. F. Groat. (Abstract No. 36-9-369.)

69. Corrections for the moments of a frequency distribution in two variables, by Dr. W. D. Baten. (Abstract No. 36-9-370.)

70. Moderately thick circular plates with plane faces, by Professor H. W. Sibert. (Abstract No. 36-9-371-t.)

71. Correlation coefficients and transforma!ion of axes, by Miss Marian A. Wilder. (Abstract No. 36-9-372-t.)

72. Linear transformations in conjugate abstract spaces, by Dr. A. C. Berry (National Research Fellow). (Abstract No. 369-373-t.)

73. On conservative transformations connected with certain harmonic functions, by Dr. Hillel Poritsky. (Abstract No. 369-374-t.)

74. Problems of closest approximation connected with the solution of linear differential equations, by Professor W. H. McEwen. (Abstract No. 36-9-375-t.)

75. Capacity of sets of Cantor type, by Professor O. D. Kellogg. (Abstract No. 36-9-376-t.)

76. On the Pade approximants associated with certain convergent series, by Professor H. S. Wall. (Abstract No. 36-9377.)

77. A further note on singular points of the differential equation $d x / X(x, y)=d y / Y(x, y)$, by Dr. C. I. Lubin. (Abstract No. 36-9-378-t.)

78. A solution of a problem of Birkhoff, by Dr. W. J. Trjitzinsky (National Research Fellow). (Abstract No. 36-9379.)

R. G. D. Richardson, Secretary 